\title{
THE FINE STRUCTURAL STUDY ON BLOOD VESSELS WITHIN HUMAN BRAIN TUMORS
}

\author{
SEIICHI IN \\ Department of Neurosurgery and Institute of Brain Diseases, \\ Kurume University School of Medicine, Kurume, 830, Japan
}

(Received for publication November 27, 1976)

The blood vessels of human brain tumors were studied in comparison with normal architecture under electron microscope.

1) In benign glial tumors, their blood vessels were apperently similar to those of normal tissue.

2) In malignant glial tumors, immature vessels were observed as might be expected in young, immature cells. The nucleus-cytoplasm ratio was high, and cytoplasm was filled with an abundance of organelles, especially free ribosomes and mitochondria. These findings suggest a high metabolic activity of endothelium. Opened intercellular junction, increased pinocytotic and coated vesicles were recognized in the endothelial cells, and proliferated endothelial cells had irregular luminal surface and elongated processes. These facts suggest an increased capacity to trasfer materials between the luman and the parenchyma.

3) In non-glial tumors, a fenestrated endothelium was commonly observed. The perivascular basement membrane was often reduplicated and was composed of several layers.

4) Adhesive devices between adjacent endothelial cells presented commonly macula adherens and desmosome-like pattern.

5) Tubular bodies were observed in the vascular endothelial cytoplasm of glioblastoma multiforme, pinealoma, craniopharyngioma, astrocytoma, teratoma with choriocarcinoma and pituitary adenoma. These tubular bodies showed various spectra from immature type to mature, might reflect a marked vascular reaction in angiogenesis with brain tumor formation.

6) Furthermore, in the case of pinealoma, its vascular basement membrane filled with collagen fibers and some dense materials merged continuously into the intercellular space of tumor tissue as seen in meningioma. These facts suggest that the origin of the pinealoma might be the mesodermal tissue.

This work was parlty presented at the 34 th Japan Neurosurgical Society (1975). 


\section{INTRODUCTION}

The bulk of the fine structural studies on human brain tumor cells have been reported with advance of electron microscopy (Luse, 1960 ; Raimondi, 1962 ; Poon et al., 1971). In recent years, several studies on the architecture of blcod vessel within brain tumors have been reported (Moriyasu et al., 1971 ; Hirano et al., 1972 ; Long, 1970, 1973 ; Tsuchida, 1974). According to these works, coincidence of opinions has not been yet accepted whether the intercellular junction between adjacent endothelial cells is opened or closed in human glioma. For example, Long (1970) described that opened intercellular junctions were observed in malignant brain tumors and this finding was seemed to related to permeability of the bloodbrain barrier. Tsuchida (1974) and Hirano (1974), on the contrary, described only little separation of intercellular junction was observed in malignant brain tumors and separation of junction observed by Long was not seen in glioma but in cerebral sarcomas. Thus, the fine structure of the endothelial cell cytoplasm is still obscure in the present time. Accordingly, this study was carried out in order to confirm the fine structure of new vessels with growth of various human brain tumors as com-

TABLE 1

Classification and location of glial tumors

\begin{tabular}{|c|c|c|c|c|c|}
\hline & Case & Age & Sex & Location & Histological diagnosis \\
\hline 1 & R.M. & 56 & $\mathrm{~F}$ & RT. frontal & astrocytoma \\
\hline 2 & S.N. & 35 & $\mathrm{~F}$ & RT. frontal & oligodendroglioma \\
\hline 3 & Y.T. & 51 & $\mathrm{~F}$ & RT. fronto-temporal & glioblastoma multiforme \\
\hline 4 & T. O. & 42 & $\mathrm{M}$ & RT. fronto-parietal & glioblastoma multiforme \\
\hline 5 & F.O. & 45 & $\mathrm{~F}$ & LT. temporal & glioblastoma multiforme \\
\hline 6 & K. Y. & 3 & $\mathrm{M}$ & LT. cerebellum & astrocytoma \\
\hline 7 & Y. T. & 51 & $\mathrm{~F}$ & RT. fronto-temporal & glioblastoma multiforme \\
\hline 8 & T. A. & 10 & $\mathrm{~F}$ & fornix & glioblastoma multiforme \\
\hline 9 & M.W. & 29 & $\mathrm{M}$ & LT. frontal & astrocytoma \\
\hline 10 & M. T. & 6 & M & III rd ventricle & astrocytoma \\
\hline 11 & Y.O. & 34 & M & RT. temporo-parietal & glioblastoma multiforme \\
\hline 12 & S. T. & 24 & $\mathrm{~F}$ & RT. cerebellar hemisphere & astrocytoma \\
\hline 13 & H. N. & 54 & $\mathrm{~F}$ & corpus callosum & glioblastoma multiforme \\
\hline 14 & H. K. & 54 & $\mathrm{M}$ & RT. temporal & glioblastoma multiforme \\
\hline 15 & Y.M. & 34 & $\mathrm{M}$ & $\mathrm{RT}$. frontal & oligodendrog ioma \\
\hline 16 & $\mathrm{~K} . \mathrm{K}$. & 36 & $\mathrm{~F}$ & RT. temporal & astrocytoma \\
\hline 17 & N.O. & 44 & $\mathrm{M}$ & LT. parietal & glioblastoma multiforme \\
\hline 18 & S.A. & 33 & M & LT. frontal & astrocytoma \\
\hline 19 & F. T. & 42 & $\mathrm{~F}$ & III rd ventricle & glioblastoma multiforme \\
\hline 20 & Y.Y. & 1 & $\mathrm{~F}$ & LT. cerebellar hemisphere & astrocytoma \\
\hline 21 & H. D. & 43 & M & Bilat. frontal & glioblastoma multiforme \\
\hline 22 & H. H. & 34 & M & RT. frontal & glioblastoma multiforme \\
\hline 23 & M. F. & 60 & M & cerebellar midline & glioblastoma multiforme \\
\hline 24 & H. H. & 52 & $\mathrm{~F}$ & LT. parieto-occipital & glioblastoma multiforme \\
\hline 25 & N. I . & 52 & $\mathrm{~F}$ & RT. frontal & astroblastoma \\
\hline
\end{tabular}


pared to those of normal brain. And more the author observed the distinct difference between the fine structure of the endothelial cell in glial tumors and in non-glial tumors.

\section{MATERIALS AND METHODS}

Human brain and spinal tumors which examined in this study were obtained in surgical operation at our Department of Neurosurgery. Fifty-seven materials were 25 glioma, 11 meningiomas, 6 neurinomas (2 spinal regions), 2 hemangiomas, 3 craniopharyngiomas, 2 pinealomas, 2 pituitary adenomas, 1 malignant lymphoma, 1 teratoma with choriocarcinoma and 4 metastatic tumors (Tables 1 and 2). The specimens of

TABLE 2

Classification and location of non-glial tumors

\begin{tabular}{|c|c|c|c|c|c|}
\hline & Case & Age & Sex & Location & Histological diagnosis \\
\hline 1 & $\mathrm{~S} \cdot \mathrm{N}$ & 30 & $\mathrm{~F}$ & RT. parietal convexity & meningothelial mening ioma \\
\hline 2 & K. O. & 58 & $\mathrm{~F}$ & parasellar & meningothelial meningioma \\
\hline 3 & N. I . & 30 & $\mathrm{~F}$ & parasellar & meningothelial meningioma \\
\hline 4 & $\mathrm{~T} \cdot \mathrm{I}$ & 55 & $\mathrm{~F}$ & RT. sphenoidal ridge & meningothelial meningioma \\
\hline 5 & A. Y. & 45 & $\mathrm{~F}$ & RT. frontal convexity & meningothelial mening ioma \\
\hline 6 & $\mathrm{~T} \cdot \mathrm{M}$ & 60 & M & suprasellar & meningothelial meningioma \\
\hline 7 & $\mathrm{~K} \cdot \mathrm{Y}$ & 44 & $\mathrm{~F}$ & suprasellar & meningothelial meningioma \\
\hline 8 & $\mathrm{~T} \cdot \mathrm{Y}$ & 52 & $\mathrm{~F}$ & RT. frontal convexity & meningothelial meningioma \\
\hline 9 & $\mathrm{~K} \cdot \mathrm{Y}$ & 44 & $\mathrm{M}$ & LT. parasagittal & meningothelial meningioma \\
\hline 10 & $\mathrm{~S} \cdot \mathrm{M}$ & 43 & $\mathrm{~F}$ & LT. sphenoidal ridge & meningothelial meningioma \\
\hline 11 & S.M. & 49 & $\mathrm{~F}$ & tentorium & fibroblastic meningioma \\
\hline 12 & H. S. & 10 & $\mathrm{M}$ & III rd ventricle & teratoma with choriocarcinoma \\
\hline 13 & F.N. & 13 & $\mathrm{M}$ & III rd ventricle & two cell pattern pincaloma \\
\hline 14 & T. S. & 1 & $\mathrm{~F}$ & III rd ventricle & unclassified \\
\hline 15 & S. K. & 51 & $\mathrm{~F}$ & sellar & choromobe pituitary adenoma \\
\hline 16 & A. T. & 44 & $\mathrm{~F}$ & sellar & acidophil pituitary adenoma \\
\hline 17 & $\mathrm{~T} \cdot \mathrm{Y}$ & 27 & M & suprasellar & craniopharyngioma (recurrence) \\
\hline 18 & $\mathrm{~T} \cdot \mathrm{S}$ & 10 & $\mathrm{M}$ & suprasellar & craniopharyngioma (recurrence) \\
\hline 19 & $\mathrm{~K} \cdot \mathrm{N}$ & 7 & M & suprasellar & craniopharyngioma \\
\hline 20 & $\mathrm{~T} \cdot \mathrm{I}$ & 25 & $\mathrm{~F}$ & LT. cerebello-pontine angle & neurinoma \\
\hline 21 & $\mathrm{Y} \cdot \mathrm{M}$ & 59 & $\mathrm{~F}$ & RT. cerebello-pontine angle & neurinoma \\
\hline 22 & $\mathrm{~T} \cdot \mathrm{M}$ & 43 & $\mathrm{M}$ & LT. cerebello-pontine angle & neurinoma \\
\hline 23 & $\mathrm{I} \cdot \mathrm{M}$ & 59 & $\mathrm{~F}$ & $\mathrm{C}_{6-7}$ & neurinoma \\
\hline 24 & T. O. & 27 & M & $\mathrm{C}_{2-6}$ & neurinoma \\
\hline 25 & F.K. & .38 & $\mathrm{~F}$ & RT. cerebello-pontine angle & neurinoma \\
\hline 26 & K. I . & 45 & $\mathrm{~F}$ & Bilat. frontal & malignant lymphoma \\
\hline 27 & T. S. & 69 & M & RT. $1 / 3$ ant. falx & hemangioma \\
\hline 28 & F.K. & 42 & $\mathrm{~F}$ & RT. parasellar & cavernous hemangioma \\
\hline 29 & $\mathrm{~T} \cdot \mathrm{N}$ & 68 & $\mathrm{~F}$ & sphenoid ridge & squamous cell carcinoma \\
\hline 30 & S.H. & 52 & $\mathrm{M}$ & RT. parietal & unclassified \\
\hline 31 & M. C. & 66 & M & LT. temporal & papillary adenocarcinoma \\
\hline 32 & S. E. & 56 & M & corpus callosum & unclassified \\
\hline
\end{tabular}


tumor removed at the time of operation were examined with electron microscope. Immediately after the removal, small pieces of the tumor were fixed by immersion in chilled cacodylate bufferied $2.5 \%$ Glutaraldehyde for two hours at $\mathrm{pH}$ 7.4. The tissue was further cut into pieces $1 \mathrm{~mm}^{3}$, washed in cacodylate buffer sucrose for 15 to 30 minutes and subsequently immersed in $1 \%$ osmium tetroxide (Millonig) for two hours. The tissue was dehydrated by passage through a graded series of acetons and propyrene oxide, following which was embedded in Epon prior to thin sectioning. Approximately $1 \mu$ thick sections were cut and were stained with Toluidine blue for light microscopic examination. The thin sections with L.K.B. ultramicrotome, prepared from appropriate in Hitachi HU-12As or Nihondenshi T7s electron microscope. Additional samples of the tumor were submitted for ordinary histologic preparation. Histological diagnosis was made on the basis of characteristic light microscopic features. To obtain information on the configuration of the normal cerebral capillary, samples of normal brain were removed from three patients during the course of surgical approach to the deep lesion.

\section{RESULTS}

\section{Normal tissues (Figs. 1 and 2)}

Normal brain tissues were obtained during surgical procedure of brain tumors situated in the deep lesions.

Normal cerebral capillary had continuous endothelial cells and its perivascular basement membrane showed no hypertrophy (Fig. 1). The adjacent endothelial cells junction was of the tight junction without gap junction (Fig. 2). In the endothelial cytoplasm there was severe paucity of pinocytotic, coated vesicles and not increased in the number of other cytoplasm organelles. No villous process was observed on the luminal surface and were observed at all no collagen fibers, fibroblasts in the endothelial basement membrane. The perivascular basement membrane was completely invested by astrocytic processes and clearly separated from the normal parenchyma, and more the extracellular space was not seen.

\section{Glial tumors (Figs. 3-10)}

As shown in Table 1, twenty-five cases were examined. Glial tumors examined were 14 glioblastomas, 8 astrocytomas, 1 astroblastoma and 2 oligodendrogliomas.

The structure of blood vessels within glioma was diversified as seen in Figs. 3-5. In benign glioma (e. g. astrocytoma, oligodendroglioma) its vessel was apparently similar to normal one (Fig. 3) and in malignant glioma such as glioblastoma multiforme an immature blood vessel was frequently observed (Fig. 4). The nucleus-cytoplasm ratio was high, and endothelial cytoplasm was filled with an abundance of free ribosomes, pinocytotic vesicles, filaments as well as usual organelles such as mitochondria, rough endoplasmic reticulum, Golgi apparatus. The endothelial basement membrane was edematously and was often redundant. It was sometimes observed that the pricyte was distented due to perivascular edema (Fig. 5), and also the basement membrane contained abundant collagen fibers. This endothelial basement membrane abutted on another basement membrane completely separated it from the tumor tissue. Although the latter was invested by processes of tumor cells, occasionally these processes were more edematous and the extracellular 
space was more distended as compared with those seen in normal tissue. Furthermore, the proliferated endothelia with irregular luminal surface and villous processes were frequently observed. Macula adherens and desmosomelike pattern were commonly observed on the intercellular junction (Fig. 6). In the case of cerebellar astrocytoma (see Table 1, case 22), opened junction in the vascular endothelium was seen in the vessels of the mural nodule (Figs. 7-9). Tubular bodies were occasionally seen in the endothelial cytoplasm of gliomas. In addition, the vascular changes after BAR therapy for malignant gliomas were shown as Fig. 10. The endothelial cell showed filamentous degeneration, which was very electron dense due to endothelium contraction. The numerous villous processes were seen on the luminal surface. The endothelial basement membrane showed electron-lucid with cloudy appearance.

\section{Menigiomas (Figs. 11-13)}

Eleven meningiomas were studied, histologically, 1 fibroblastic type and 7 meningothelial types. Fenestrated capillaries were observed in the endothelial cells of meningiomas. Numerous pinocytotic, coated vesicles were seen in the endothelial cytoplasm. Coated vesicles, rare component of the normal adult cerebral vessel, were easily found in vessels of tumors, especially in recurrent meningiomas. The vascular basement membrane was filled with collagen fibers and often showed reduplication. This basement membrane was directly close to tumor cells filled tonofilaments without another membrane separating from the tumor tissue as seen in the vessel of glioma. Futhermore, in the vascular endothelial cytoplasm of meningioma, tubular bodies were ocassionally observed. Even in this tumor, one of benign ones, immature vessels were seen in the course of growth of new vessels and in the endothelial cytoplasm pinocytotic vesicles were much more seen than in the vessels commonly supplying meningioma (Figs. 12 and 13).

\section{Pituitary adenomas (Figs. 14 and 15)}

Two pituitary adenomas examined were respectively chromophobe and acidophilic type. Both in chromophobe and acidophilic adenomas each vascular structure presented similar pattern, and fenestrations were in the whole surrounding of endothelium (Figs. 14 and 15). The vascular basement membrane was reduplicated and was surrounded by tumor cells with many membranelimited granules seen around the plasma membrane. The endothelial cytoplasm contained tubular bodies, numerous pinocytotic vesicles as well as usual organelles.

\section{Neurinomas (Fig. 16)}

Six neurinomas were examined. Four were tumors from the acoustic nerves and two was extramedullary tumors from the cervical cord. In all cases of neurinomas, most vessels showed numerous fenestrae.

The endothelial cells were extremely attenuated except for nuclear area where cytoplasm was abundant and where pinocytotic vesicles and other usual organelles were present. In the attenuated areas, numerous fenestrae with diaphragmas were present. The vessel was surrounded by proliferated, reduplicated basement membrane which contained amounts of collagen fibers and its surrounding perivascular space 
was found closely with numerous tumor cells surrounded their intrinsic basement membrane.

\section{Craniopharyngiomas (Fig. 17)}

Three craniopharyngiomas were studied. Histologically, they showed the squamous epithelial type. The vessel was found in the connective stroma which separated the tumor cell nests. Between tumor cells and the vessels collagen filled extracellular space intervened. The endothelium of the small vessel was surrounded by a basement membrane which was reduplicated and showed sometimes several layers. The endothelium contained pinocytotic vesicles, coated vesicles, tubular bodies as well as usual organelles. The endothelial cytoplasm was very attenuated and several fenestrations were visible (Fig. 17). However, in the gliotic areas obtained at the time when the case of No. 27 (see Table 2) was reoperated, the vessels lacked fenestration.

\section{Pinealoma (Figs. 18 and 19)}

Although only one pinealoma was examined, several interesting findings were present, the vessels supplying the pinealoma similarly had fenestrations as those seen in normal pineal body (Hattori, 1972). Secondly, many tubular bodies were also seen in the endothelial cytoplasm (Fig. 18). The basement membrane filled with collagen fibers and some dense materials merged continuously into the intercellular space within tumor tissue as seen in meningiomas. Pinocytotic vesicles, coated vesicles were seen in the endothelial cytoplasm.

Teratoma with choriocarcinoma (Figs. 20 and 21)
This tumor was located in the posterior third ventricle. Many tubular bodies were observed in the vascular endothelium (Fig. 20). To author's examination, any fenestration could not be observed (Fig. 21).

\section{Hemangiomas (Fig. 22)}

Two hemangiomas were examined and in both tumor vessels fenestrations were observed (Fig. 22). Collagen-filled perivascular basement membrane was visible. In the endothelial cytoplasm, pinocytotic vesicles, coated vesicles were increased as those observed in the vessels of other intracranial tumors.

\section{Malignant lymphoma and metastatic tumors (Fig. 23)}

One malignant lymphoma and four metastatic brain tumors were studied. Occasionally, the endothelial fenestrations were visible.

\section{DISCUSSION}

The capillaries within brain tumors can be divided into two categories on the basis of the presence or the absence of fenestration.

Fenestrated capillaries were seen in most ones supplying non-glial tumors. The endothelial cytoplasm was very attenuated and small pores were present. As many other workers (Majno, 1965 ; Bennet et al., 1959) reported, the pores consited of circular regions, 400$600 \AA$ in diameter, and very thin, $50 \AA$ diaphragmas were seen separating the vascular lumen from the perivascular space in the present observation. These fenestrations were found in associated with a distended perivascular space, permitting the flow of materials direc- 
tly from the lumen into the perivascular space. In the present study, these fenestrations were found in vessels of neurinoma, meningioma, pituitary adenoma, pinealoma, craniopharyngioma, hemangioma and metastatic brain tumors. This similar fenestration has been reported in other tumors, such as choroid plexus papilloma (Carter et al., 1972), hemangioblastoma (Tani et al., 1974), hemangiopericytoma and hemangioendothelioma (Ramsey, 1966), melanoma (Ward et al., 1974), optic glioma in the vicinity of the chiasma (Miki and Hirano, 1975), metastatic renal carcinoma (Hirano and Zimmerman, 1972) and malignant lymphoma (Hirano et al., 1974). Metastatic brain tumor contained fenestrated capillaries similar to those in in situ primary tumor or in the parent organ. This fact suggests that metastatic tumors growing in the brain caused differentiation of non-fenestrated cerebral blood vessels which infiltrated the tumor, as Hirano and Zimmerman concluded (1972). It may be considerable that the tumors of areas normally fenestrated capillaries show consequently fenestrations (e. g. pituitary adenoma, pinealoma, choroid plexus papilloma etc.). In the case of the neoplasm which proliferates or involves in the vicinity of regions supplied by normally fenestrated capillaries (e. g. craniopharyngioma, this tumor is usually found between the hypothalamus and the pituitary gland in which regions are known to contain normally fenestrated ones), two possibilities may be postulated. The first, tumor is supplied by already fenestrated capillaries. The second, some specific change in the cell's ability to influence blood vessels development due to the neoplastic transformation. Even in the cases of that the position of the tumors indicates that they were not in the vicinity of areas normally supplied by fenestrated capillaries, they are occasionally found (e.g. neurinoma, meningioma, vascular neoplasm etc). It may be considerable that these facts might support the second possibility as mentioned above. Therefore; on the basis of the presence of fenestrations, as Hirano and Zimmerman (1972) concluded, it may be suggested that blood vessel development is determined by the immediate environment and not the nature of the confluent vessels. It is well known that these tumors supplied by fenestrated capillaries often result in an elevated protein content in CSF and that they frequently from large cysts (Schechter, 1967 ; Hirano et al., 1972 ; Ward, 1974; Hirano, 1974). It is also speculated that the result of focal hemorrhage within these tumors is due to such a vascular condition (Hirano et al., 1972). In studies on the permeability characteristics of capillaries in brain tumors supplied by fenestrated ones, Brightman (1971), using virally induced brain tumor, reported changes in capillary permeability which, in some instances, could be correlated with the formation of fenestrations.

Opened junction between endothelia was observed in some vessels of the mural nodule in the case of cerebellar astrocytoma (see Table 1) which was confined to the cerebellar hemisphere and was distant from the areas supplied by normally fenestrated blood vessels. It was found to be well circumscribed within cyst at the time of operation. However, according to the present study, a typical tight junction was not commonly but splitting of the intermediated line, macula adherens and desmosome-like pattern was commonly observed in the endothelial junction within glial tumors. Long (1970), utilizing lanthanum as a tracer, reported the capillary ultrastructure in 
19 malignant brain tumors. According to his report, some of these intercellulàr junctions between adjacent endothelial cells were apparently patent allowing the free passage of lanthanum through the opened junctions from the capillary lumen in to the basement membrane, and the extracellular space. $\mathrm{He}$ postulated this fact accounted for the absence of the blood-brain barrier in human malignant brain tumors. According to some workers (Hirano, 1974; Tsuchida, 1974), on the contrary, only little separation of junction had been seen in glioma. They suggest that such separation of junction observed by Long was not seen in glioma but in cerebral sarcoma. However, the auther's study support Long's reports (1970, 1973), and Vick's one (1972). Under certain conditions, opend junction conceivably might be seen even in the vascular endothelia within glioma.

In the endothelial cytoplasm within brain tumors, the marked increased in the number of usual organelles, especially free ribosomes, were found. This fact suggests high metabolic activity of endothelial cells. Pinocytotic vesicles, which are concerned with small protein transfer across the vessel wall just as a ferry-boat (Palada, 1953, 1960 ; Bennet, 1959 ; Majno, 1965), these are normally rare but were commonly observed in the vessels within various brain tumors. Tsuchida (1974) described the absence of the blood brain barrier in human glioma might account for enhancement in vascular permeability due to increased pinocytotic vesicles in the vascular endothelia. In regard to etiology for the increased pinocytotic vesicles in capillary endothelia of brain tumors, it is still obscure at the present time. The following possibilities would be considered; 1) The breakdown of autoregulation, 2) Tissue injury or ischemic change, 3) The presence of some releasing factors for pinocytotic vesicles, might contribute to the increased in frequency of these vesicles.

Coated vesicles, $800-1200 \AA$ in diameter, which are considered to be associated with endothelial uptake of proteins (Roth and Porter, 1964). These vesicles are uncommon in the mature normal vessels but are commonly observed in immature and pathological vessels in the mammalia. In the present study, these coated vesicles tended to increase in the recurrent meningiomas. This fact suggests that the marked appearance of coated vesicles would be deeply related to the brain tumor formation.

Tubular bodies, specific organelles in the endothelial cytoplasm, were commonly observed in the blood vessels of astrocytoma, craniopharyngioma, pinealoma, teratoma with choriocarcinoma, meningioma, glioblastoma multiforme, and pituitary adenoma. They have been found to be common in certain brain tumors, medulloblastoma, ependymoblastoma, pituitary adenoma (Hirano, 1972), glioblastoma multiforme (Hirano and Matsui, 1975), craniopharyngioma (Hirano et al., 1973), and metastatic cerebellar renal carcinoma (Kawamura et al., 1974) up to this time. According to the original description by Weibel and Palade (1964), these bodies are rod-shaped, measuring $0.1 \mu \mathrm{m}$ in width and $3 \mu \mathrm{m}$ in length. They are bounded by a limiting membrane of unit membrane type and contain several small tubules, $150-200 \AA$ thick, embedded in a dense matrix, and disposed parallel to the long axis of the rod. The wall of such tubules is about $40 \AA$ thick and the intertubular distance measured 50 to $60 \AA$. The number of tubules in each rod was 10 to 30 , depending upon the sectional area. These bodies are very rare in normal cerebral capillaries and are confined to the endothelial cells are found in the vascular 
lining of the general organs, especially in the capillaries and venules than in the small arteries. These bodies have been detected in the endothelial cells of the blood vessels of animal and human pathological tissues as well as normal tissue. Morphologically, it is emphasized that these bodies would be derived from the Golgi apparatus, and recently Kawamura et al (1974) reported these bodies were occasionally observed connecting with either coated vesicles or cytoplasm membrane of the endothelium. The two types of tubular bodies (one type is mature and the other is immature) were described by Matsuda and Sugiura (1970). The former reveals compact tubular structures in the matrix and the latter is an electron-lucid form because of containing prominent tubules in the rod, embeding in a relatively pale matrix. The electron-lucid tubular body has been considered to occur in the younger endothelial cells, with the organelle becoming more compact and dense it grow more mature. The observation on the growing vessels in the rabbit cornea suggests that the immature type do not become mature within two weeks after chemical stimulation (Matsuda and Sugiura, 1970). This suggests that the presence of the immature tubular body in the endothelial cytoplasm indicates immaturity of the endothelial cells. Thus, the frequent occurence of tubular bodies in the vascular endothelial cells of brain tumors might be a barometre of indicating the development of tumor vessels. It might also reflect a vascular reaction in angiogenesis with the brain tumor formation. More recently, Herringer et al (1974), reported the presence of these tubular bodies in small vessels within the adult human normal brain tissue. The function of these bodies, however, is still obscure at the present time. They might probably play an important role in the endothelial cell of blood vessels. To sum up, the frequent occurence of pinocytotic, coated vesicles and these bodies in the endothelial cytoplasm might indicate immaturity of brain tumor vessels.

Among other alterations in the endothelial cytoplasm, the abundance of filaments often found in the present study. In this regard, the possibility that the increase in endothelial filaments may represent contractile proteins which then could function to alter endothelial junctions, and affect capillary permeability (Becker, 1969). Schechter (1972) reported the possibility that this increased filaments might be related to supportive functions, even in brain tumor mass.

The results of studies on the perivascular fine structure in brain tumors are summarized as follows (Luse, 1960 ; Long, 1970, 1973 ; Moriyasu, 1971 ; Hirano et al., 1972, 1973 ; Tsuchida, 1974), 1) The basement membrane is irregularly distended, often reduplicated and contains abundant collagen fibers. 2) The perivascular space and extracellular space shows irregular width, and also the tumor cells processes distended, chiefly in glioblastoma multiforme. These findings are similar to those in brain edema. The increase in permeability and edema are characteristic in brain tumor. The similar findings obtained from the present study. The basement membrane is considered to preserve the endothelial layer and to play a role of filter system for transcapillary materials. These alterations of the basement membrane in brain tumor vessels are suggestive of abnormality of vascular permeability. Hills (1964) described disorganization of the basement membrane after ischemia, and Schechter (1972) explained the alterations in the basement membrane morphology were secondary to the break- 
down of tumor cells at the parenchymal-pericapillary interface. Furthermore, in one case of the pinealoma, the basement membrane merged continuously into the intercellular space within tumor tissue as seen in meningiomas. These facts suggest that the origin of the pinealoma might be the mesodermal tissue although it has been considered the tumor of the ectodermal tissue.

\section{ACKNOWLEDGEMENTS}

I wishes to thank Prof. S. Kuramoto, Associate Prof. M. Watanabe, Dept. of Neurosurgery, and Prof. Y. Takeshige, Associate Prof. S. Fujimoto, Dept. of First Anatomy, for valuable suggestions during the course of this study. I am also indebted to Prof. K. Inanaga, Associate Prof. S. Anraku and to Dr. H. Kojima of Institute of Brain Diseases.

\section{REFERENCES}

Bennett, H.S., Luft, J.H. and Hampton, J.C. (1959). Morphological classifications of vertebral blood capillaries. Am. J. Physiol, 196, 381-390.

BRightman, M.W., Reese, T.S., Vick, N.A. and BINGER,D.D. (1971). Mechanism underlying the lack of a blood-brain barrier to peroxidase in virally induced brain tumors. (Abstract). J. Neuropathol. Exp. Neurol., 30, 139-140.

Becker, C. G. and Murphy, G. E. (1969). Demonstration of contactile proteins in endothelium and cells of the heart valves, endocardium, intima, arteriosclerotic plaques and Aschoff bodies of rheumatic heart disease. Am. J. Paht, 55, 1-37.

CARTER, L.P., BegGS, J. and WAGgener, J.D. (1972). Ultrastructure of three choroid plexus papillomas. Cancer, 30, 1130-1136.

HATTORI, S. (1972). The distribution of exogenous ferritin in the mouse pineal body. Brain Nerve., 24, 99-105.

Herrlinger, H., Anzil, A. P., Blinzinger, K. and KRONSKI, D. (1974). Endothelial micro- tubular bodies in human brain capillaries and venules. J. Anat., 118, 205.

Hirano, A. Tomiyasu, U. and Zimmerman, H. M. (1972). The fine structure of blood vessels in chromophobe adenoma. Acta Neuropath, 22, 465-468.

Hirano, A., Dembitzer, H. M. and Zimmerman, H.M. (1972). Fenestrated blood vessels in neurilemoma. Lab. Invest., 27, 305-309.

Hirano, A. and Zimmerman, H.M. (1972). Fenestrated blood vessels in a metastatic renal carcinoma in the brain. Lab. Invest., 26, 465-458.

Hirano, A., Ghatak, N.R. and Zimmerman, H. M. (1973). Fenestrated blood vessels in craniopharyngioma. Acta Neuropath. (Berl.), 26, 171-177.

Hirano, A. (1974). Fine structural alterations of small vessels in the nervous system. In J. Cervos-Navarro (Editor): International symposium on the Pathology of Cerebral Microcirculation. Publishing House Walter de Gruyter \& Co., Berlin.

Hirano, A., Ghatak, N.R., Becker, N.H. and ZIMMERMAN, H.M. (1974). A comparison of the fine structure of small blood vessels in intracranial and retroperitoneal malignant lymphoma. Acta Neuropath, 27, 93-104.

Hirano, A. and Matsui, T. (1975). Vascular structures in brain tumors. Hum. Pathol, 6, 611-621.

Hills, C. P. (1967). Ultrastructural changes in the capillary bed of the rat cerebral cortex in anoxic-ischemic brain lesions. Am. J. Path, 50, 623-638.

Kawamura, J., Kamijyo, Y, Sunaga, T. and Nelson, E. (1974). Tubular bodies in vascular endothelium of a cerebral neoplasm. Lab. Invest. 30, 358-365.

LONG, D. M. (1970). Capillary ultrastructure and blood-brain barrier in the human malignant brain tumors. J. Neurosurg., 32, 127-144.

LoNG,D.M. (1973). Vascular ultrastructure in human meningiomas and Schwannomas. J. Neurosurg., 38, 409-419.

LUSE, S. A. (1960). Electron microscopic studies of brain tumors. Neurology., 10, 881905.

MAJNo, G. (1965). Ultrastructure of the vascular membrane. Handbook of Physiology, Section 2: Circulation, W.F. Hamilton(ed.), Vol. 111, pp. 2293-2375, American Physiolo- 
gical Society.

Matsuda, H. and Sugiura, S. (1970). Ultrastructure of "tubular body" in the endothelial cells of the ocular blood vessels. Invest. Ophthalomol., 9, 919-925.

Miki, H. and Hirano, A. (1975). Electron microscopic studies of optic nerve glioma in an 18 month old child. Am. J. Ophthal, 79, 589-595.

Moriyasu, N., Nakamura, S., Miyagami, M., Morisawa, S. and Igusa, N. (1971). The fine structure of capillary in the brain tumors. J. Electr. Micro. (Jap.), 4, 771-780.

PALAdE, G. E. (1953). Fine structure of blood capillaries. J. Appl. Phys., 24, 1424.

Palade, G. E. (1960). Transport in quanta across the endothelium of blood capillaries. Anat. Record., 136, 254.

Poon, T.P., Hirano, A. and Zimmerman, H. M. (1971). Electron Microscopic Atlas of Brain Tumors. Grune \& Stratton, Inc., New York.

Raimondi, A. J., Mullan, S. and Evans, J. P. (1962). Human brain tumors: An electroscopic study. J. Neurosurg., 19, 731-751.

RAMSEY, H. J. (1966). Fine structure of hemangiopericytoma and hemangioendothelioma. Cancer, 19, 2005-2018.

Roth, T.F. and Porter,P. (1961). Speciialzed sites on the cell surface for protein uptake.
In : Fifth International Congress for Electron Microscopy, edited by S.S. Breese, Jr. Vol. 2, Acad. Press, New York.

SCHECHTER, J. (1967). Ultrastructural changes in the capillary bed of human pituitary tumors. Amer. J. Path. 67, 109-127.

TANi, E., IKeda, K., Kudo, S. and Kamijyo, Y. (1974). Fenestrated vessels in human hemang ioblastoma. J. Neurosurg., 40, 696-705.

TsuchidA, T. (1974). A study of capillary ultrastructure of brain tumors in association with blood-brain barrier. Advanc. Neurol. Sci., 18, 106-121.

Tsuchida, T. (1974). A study of capillary ultrastructure of brain tumors in association with blood-brain barrier. Part II. - Experimental mouse brain tumors. Advanc. Neurol. Sci., 18, 155-162.

VICK, N.A. and BIGNER, D.D. (1972). Microvascular abnormalities in virally- induced canine brain tumors. Neurol. Sci., 17, 29-39. WARD, J. D., HADFIELD, M. G., Becker, D. and Lovings, E. T. (1974). Endothelial fenestrations and other vascular alterations in primary melanoma of the central nervous system. Cancer, 34, 1982-1991,

Weibel, E.R. and Palade, G. E. (1964). New cytoplasmic components in arterial endothelia. J. Cell Biol., 23, 101-112. 
In the photographs of the sections (Figs. 1 -23),

the following abbreviations are used :
A F : astrocyte processes
BM : basement membrane
C O : collagen fibers
$\mathrm{CV}$ : coated vesicles
$\mathrm{E}$ : endothelial cell cytoplasm
E S : extracellular space
F b : fibroblast
GF : glial filaments
I L : intermediate-line

$J$ : intercellular junction

$\mathrm{L}$ : capillary lumen

M : mitochondria

$P$ : pericyte

PV : pinocytotic vesicles

$\mathrm{T}$ : tumor cell

T B : tubular bodies

$\mathrm{V}$ : vacuole

V P : villous processes 

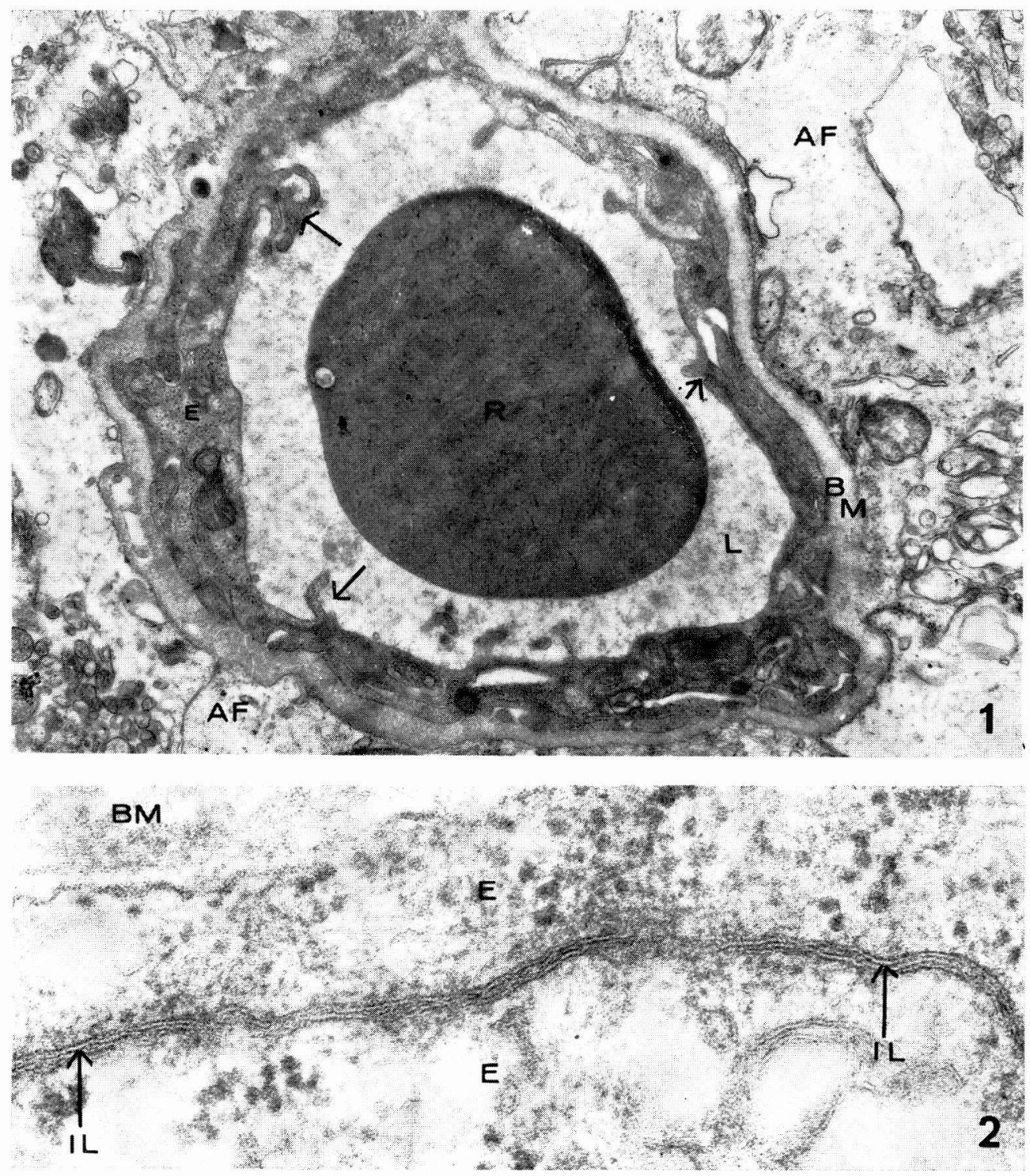

Fig. 1 Normal cerebral capillary. Arrows show endothelial cell junction. There is paucity of pinocytotic vesicles in the endothelial cytoplasm. The basement membrane shows no hypertrophy and its outer membrane is invested by a series of process of astrocytes. $\times 13,500$

Fig. 2 Tight junction between two endothelial cells in the normal brain. E, E, parts of overlaping endothelial cells. In certain segments of the intercellular junction an intermediate line is clearly seen. $\times 114,000$

Fig. 3 Capillary in an astrocytoma. The entire capillary is similar to that of the normal brain shown Fig. 1. The basement membrane is partially hypertrophied and where contains collagen fibers. $\times 12,400$

Inset: H.E. specimen astrocytoma $5 \times 20$ 

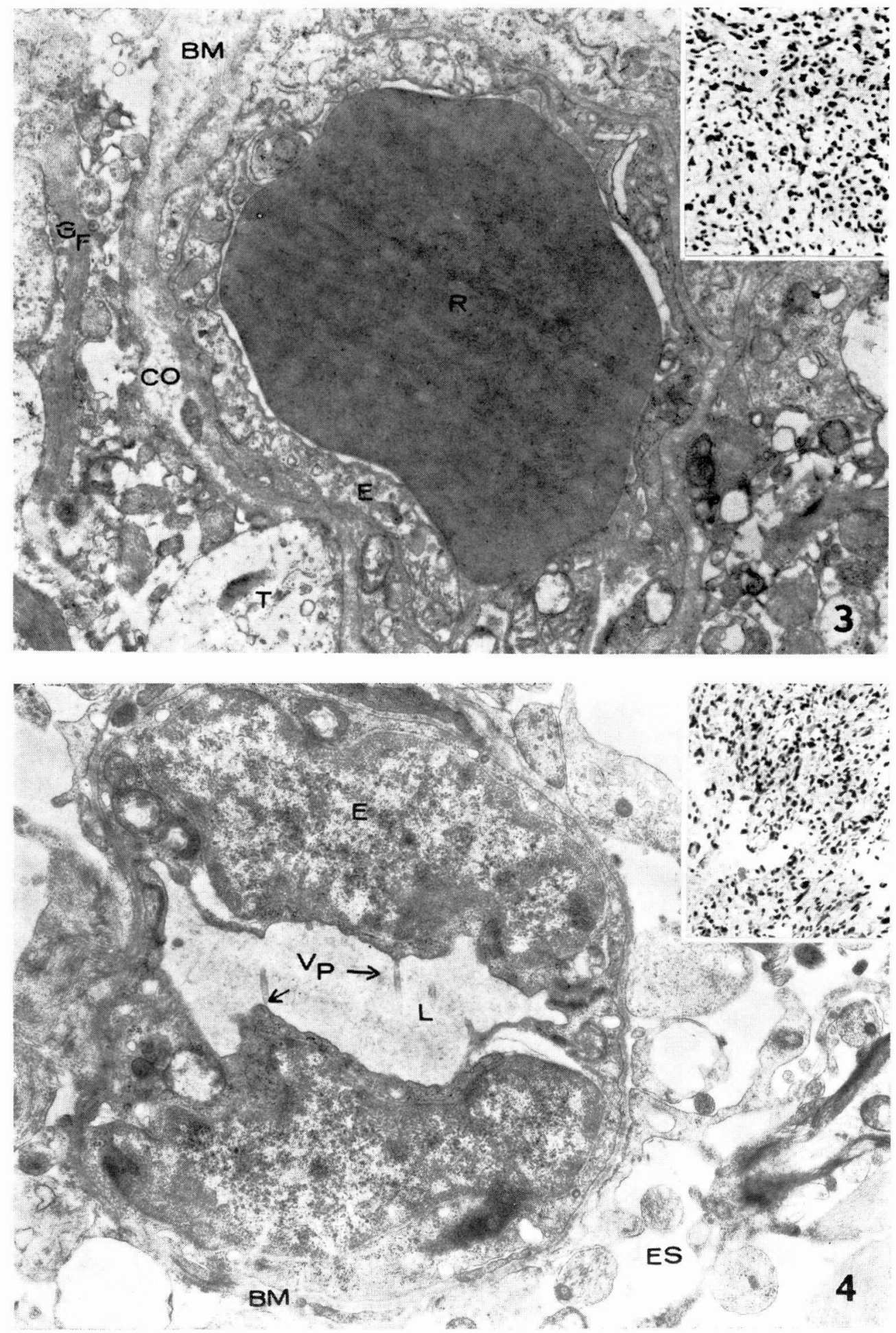

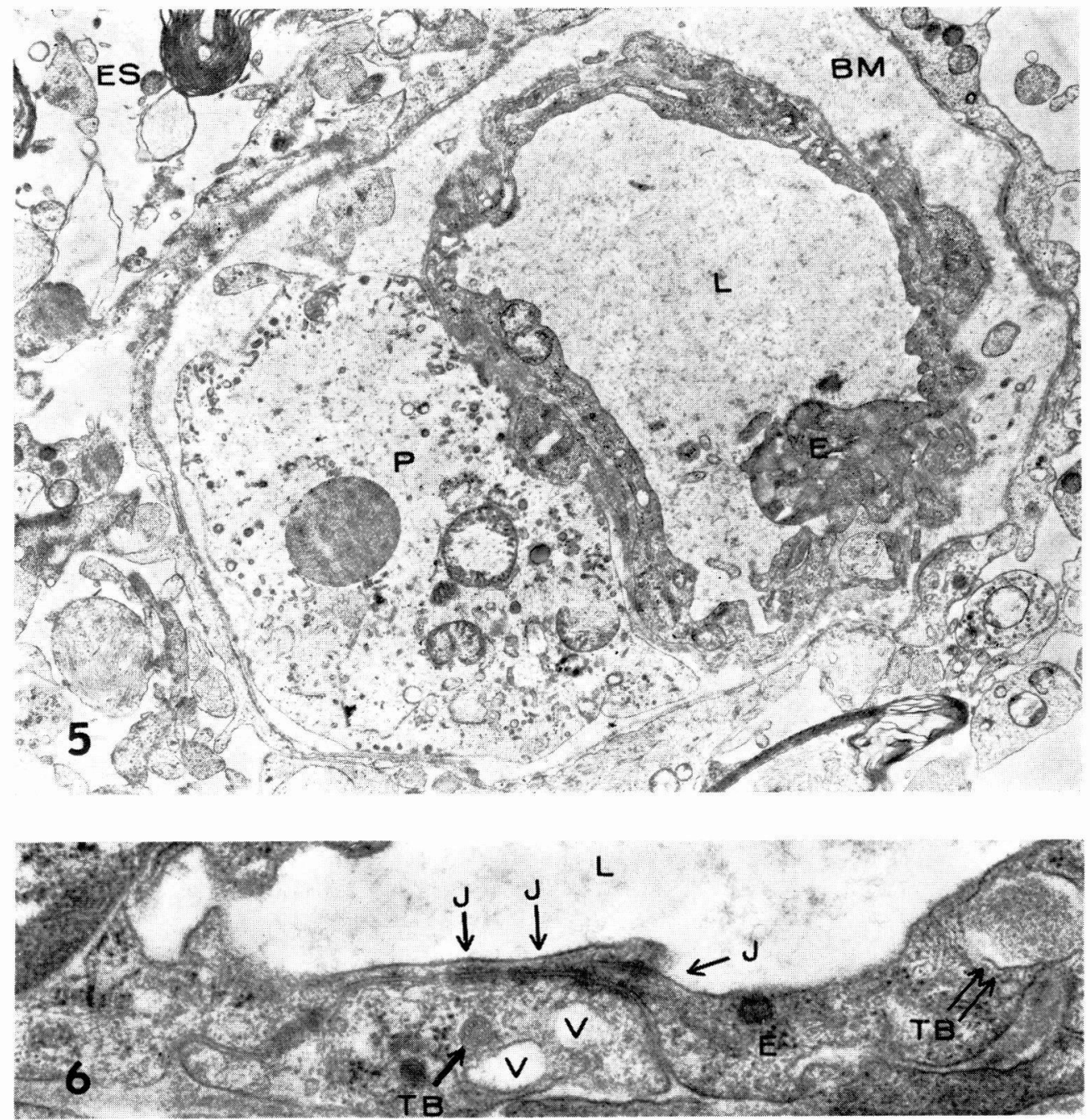

Fig. 4 Capillary in a glioblastoma multiforme. The vessel shows an immature architecture and villous processes are seen on the luminal surface. The extracellular spaceis distended. $\times 12,400$

Inset: H.E. specimen glioblastoma multiforme $5 \times 20$

Fig. 5 Capillary in a glioblastoma multiforme. The basement membrane is edematously distended and the pericyte is also distended due to perivascular edema. Proliferation is seen in a part of endothelium. $\times 7,000$

Fig. 6 Capillary in a glioblastoma multiforme. The intercellular junctions between the adjacent endothelial cells show most occasionally macula adherens and desmosomelike pattern. Arrows show mature tubular body and double arrow shows immature one. $\times 37,400$ 

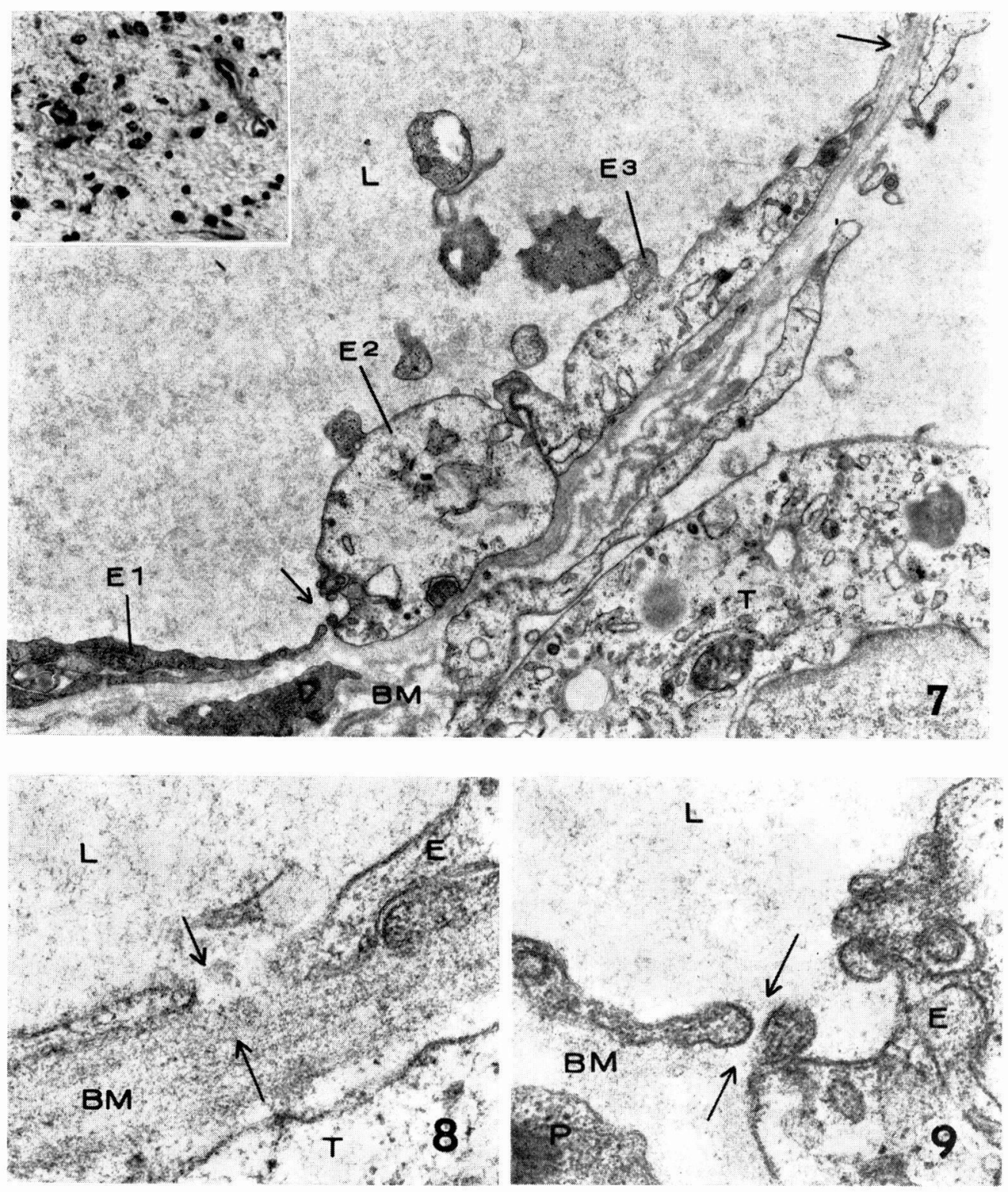

Fig. 7 Capillary in a cerebellar astrocytoma. Opened junctions (arrows) in the vascular endothelial cells are seen in the small vessels of the mural nodule of cerebellar astrocytoma. The basement membrane is reduplicated. El portion of endothelial cell with abnormally dark cytoplasm. $\times 13,300$

Inse : H. E. specimen astrocytoma $5 \times 40$

Figs. 8 and 9 High magnification views of endothelial cell junctions in Fig. 7. Arrows indicate widely opened junctions between endothelial cells with no evidence of membrane fusion. Fig. $7: \times 52,000$, Fig. $8: \times 58,500$ 


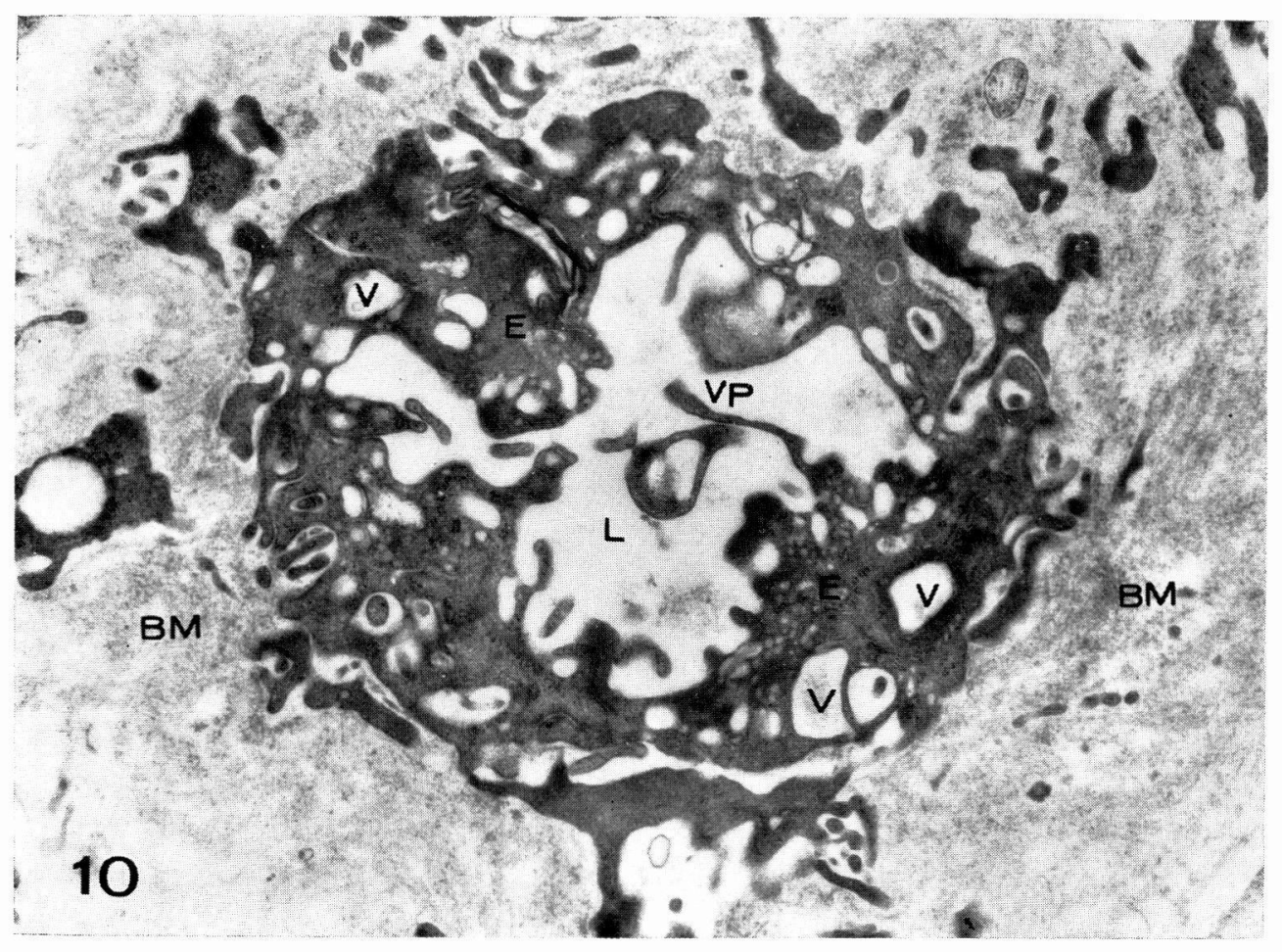

Fig. 10 Vascular changes after BAR therapy for malignant glioma. The endothelial cells show filamentous degeneration and contain numerous vacuoles. The numerous villous processes are seen on the luminal surface and the cytoplasm of these cells is very electron dense. The basement membrane denotes electron-lucid with cloudy appearance. $\times 13,300$

Fig. 11 Capillary in a meningioma. Arrows show several endothelial fenestrations. $\times 12,000$

Inset: H.E. specimen Meningotheial meningioma $5 \times 40$

Figs. 12 and 13 Immature vessels in meningiomas. Numerous pinocytotic, coated vesicles are seen in the endothelial cytoplasm. The basement membrane is filled with collagen fibers. Fig. 12: $\times 11,000$, Fig. 13: $\times 14,500$ 

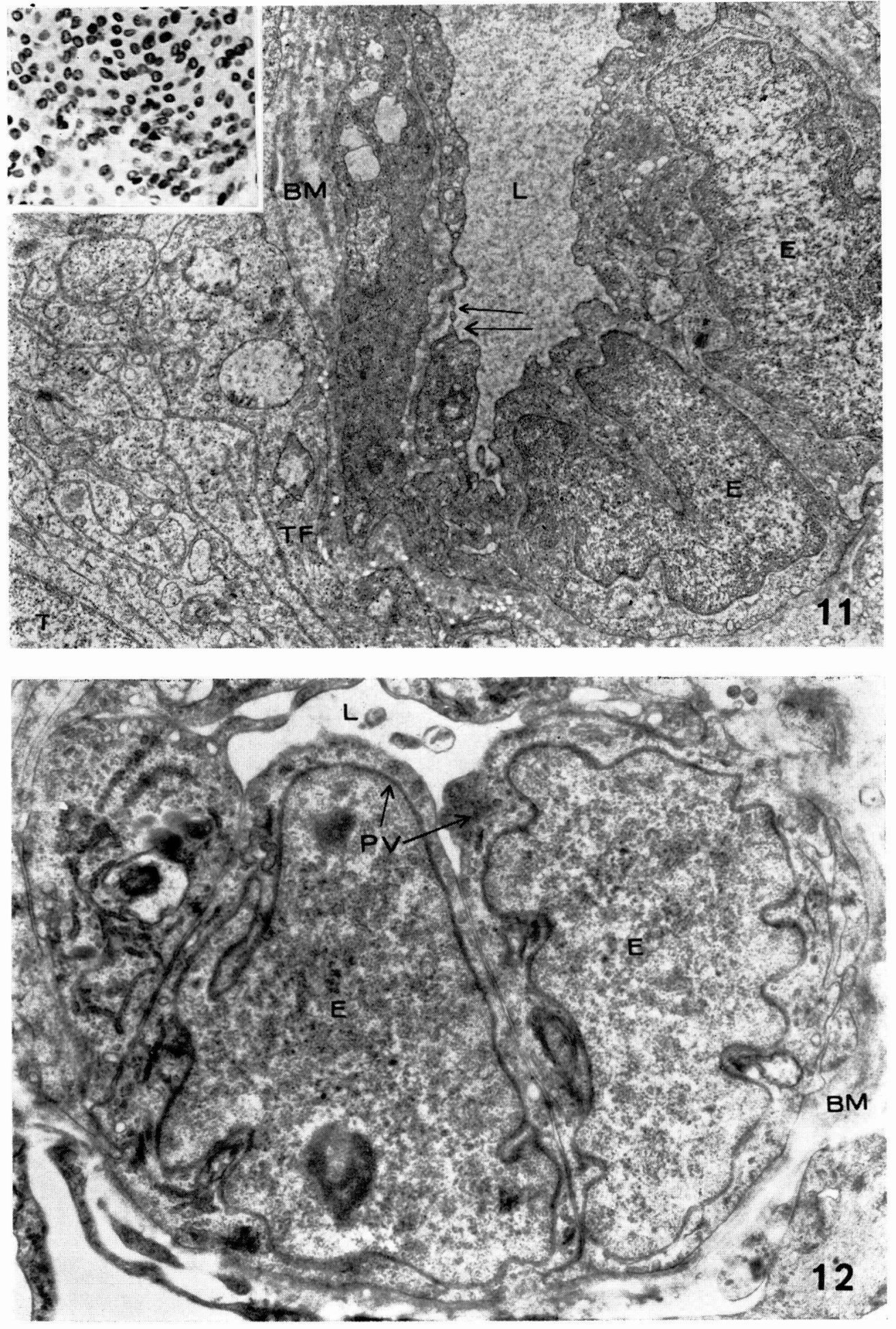


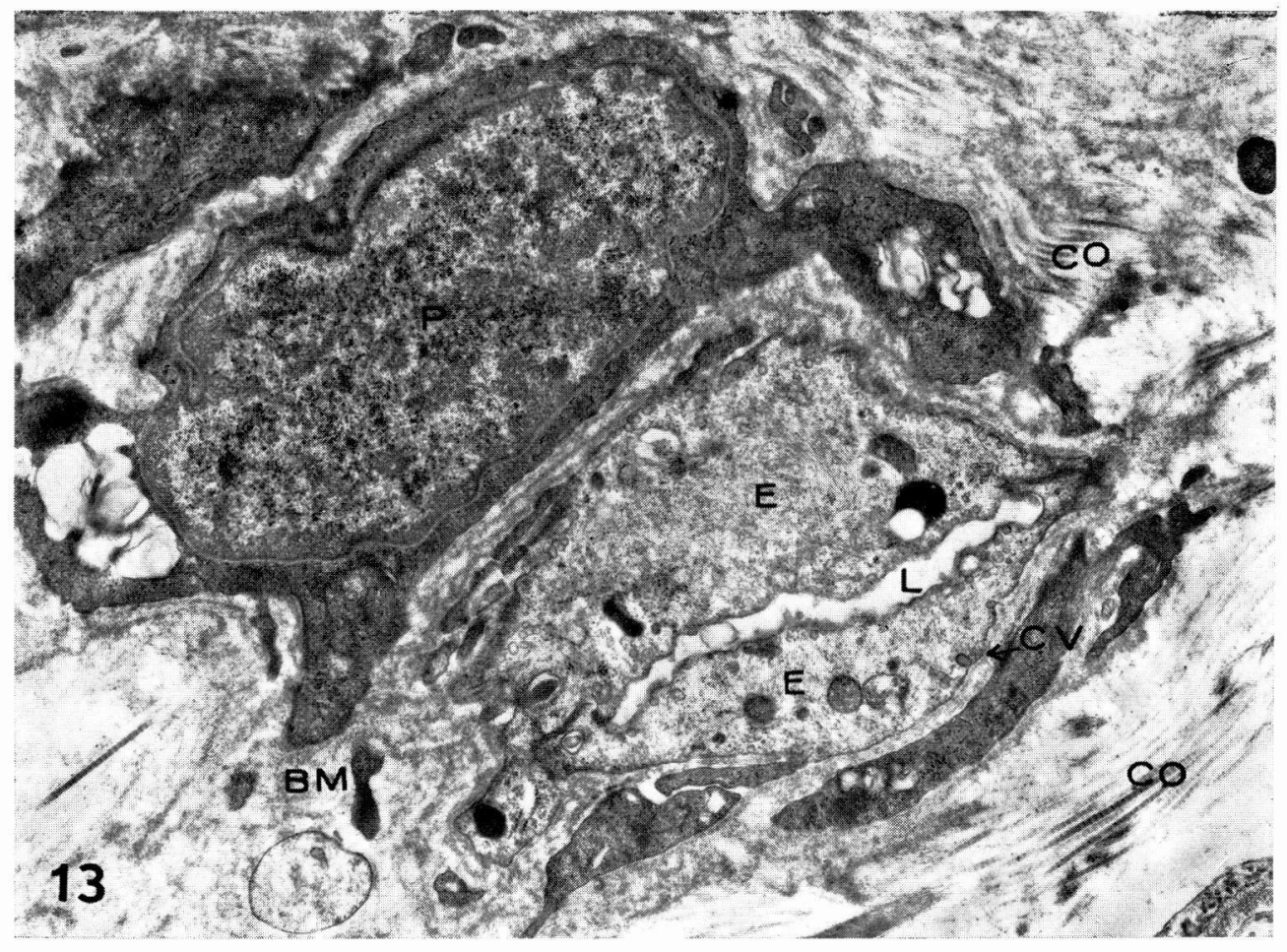

Fig. 14 Capillary in a chromophobe pituitary adenoma showing pinocytotic, coated vesicles and arrow shows endothelial fenestation. $\times 38,400$

Inset: Toluidine blue specimen Chromophobe pituitary adenoma $5 \times 40$

Fig. 15 A fenestrated blood vessels in a chromophobe pituitary adenoma. Large arrows show fenestrations. The basement membrane is loose, irregular in width and contains a few membrane limited granules (indicated by double arrows). $\times 45,700$

Fig. 16 Capillary in a neurinoma. Fenestrations are indicated by the arrows. The basement membrane is reduplicated. The tumor cells are surrounded by their intrinsic basement membrane. $\times 7,700$

Fig. 17 Capillary in a craniopharyngioma showing endothelial fenestrations. The basement membrane shows several layers, and contains collagen fibers. $\times 11,000$ Inset: H.E. specimen squamous cell type craniopharyngioma $5 \times 20$ 

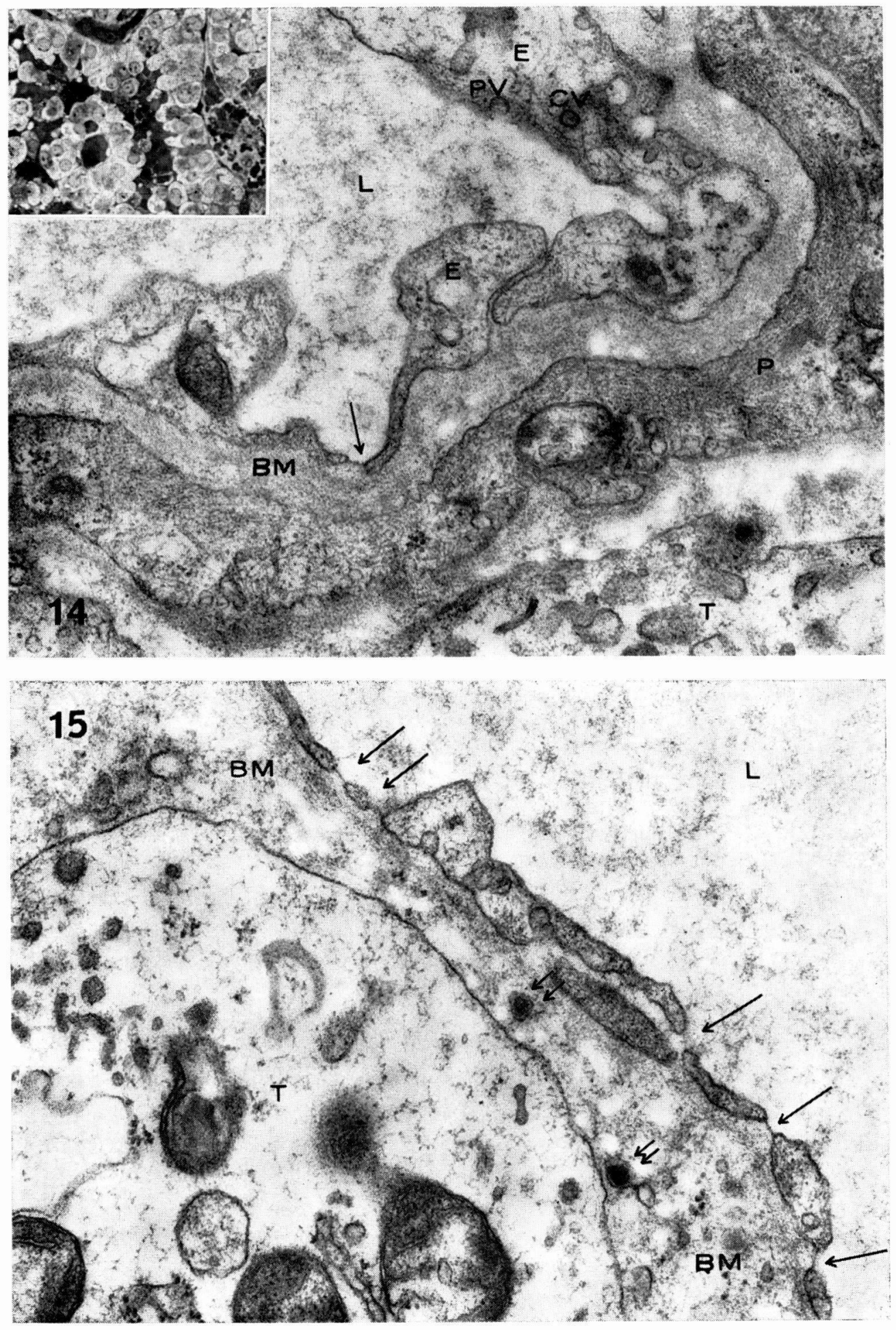

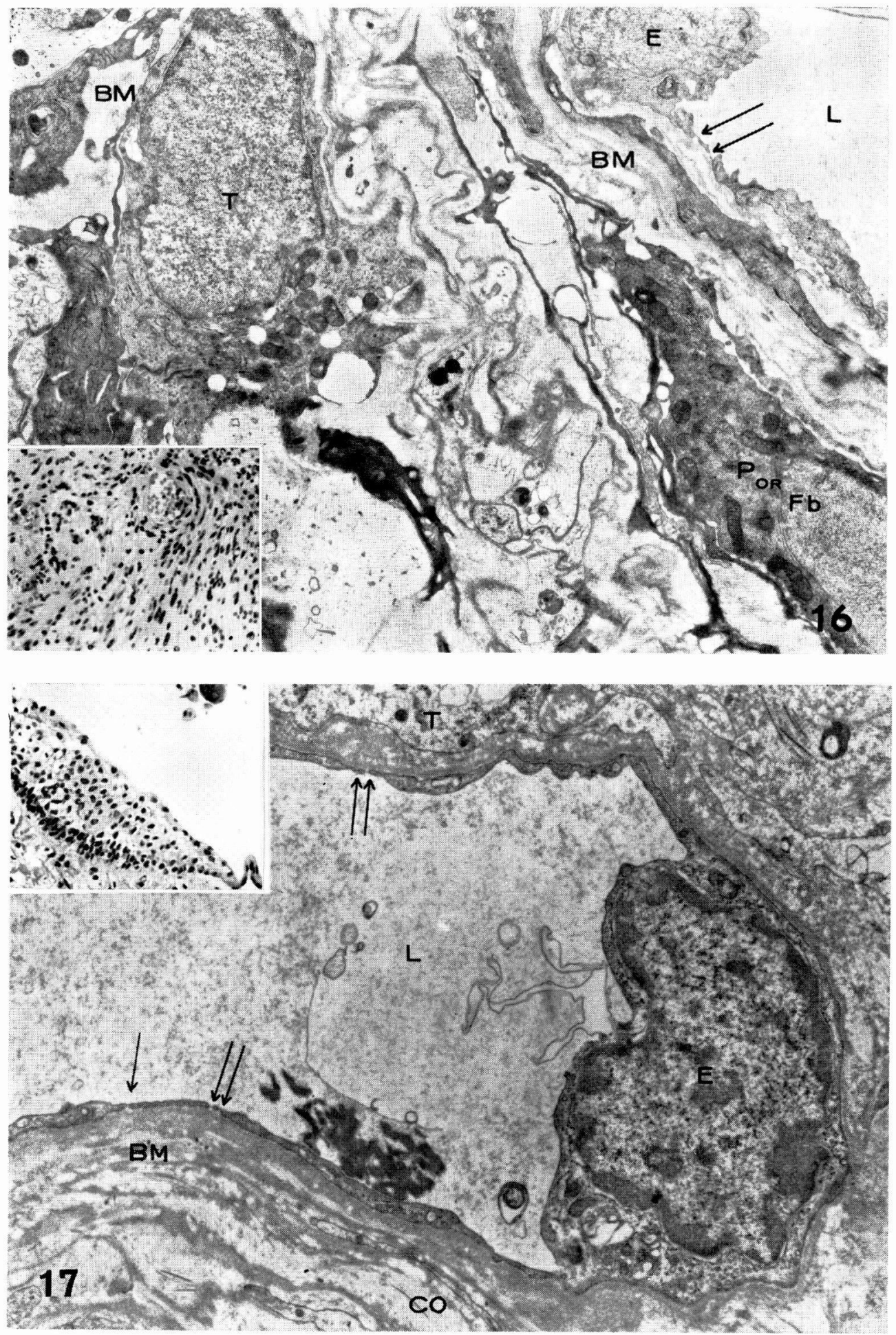

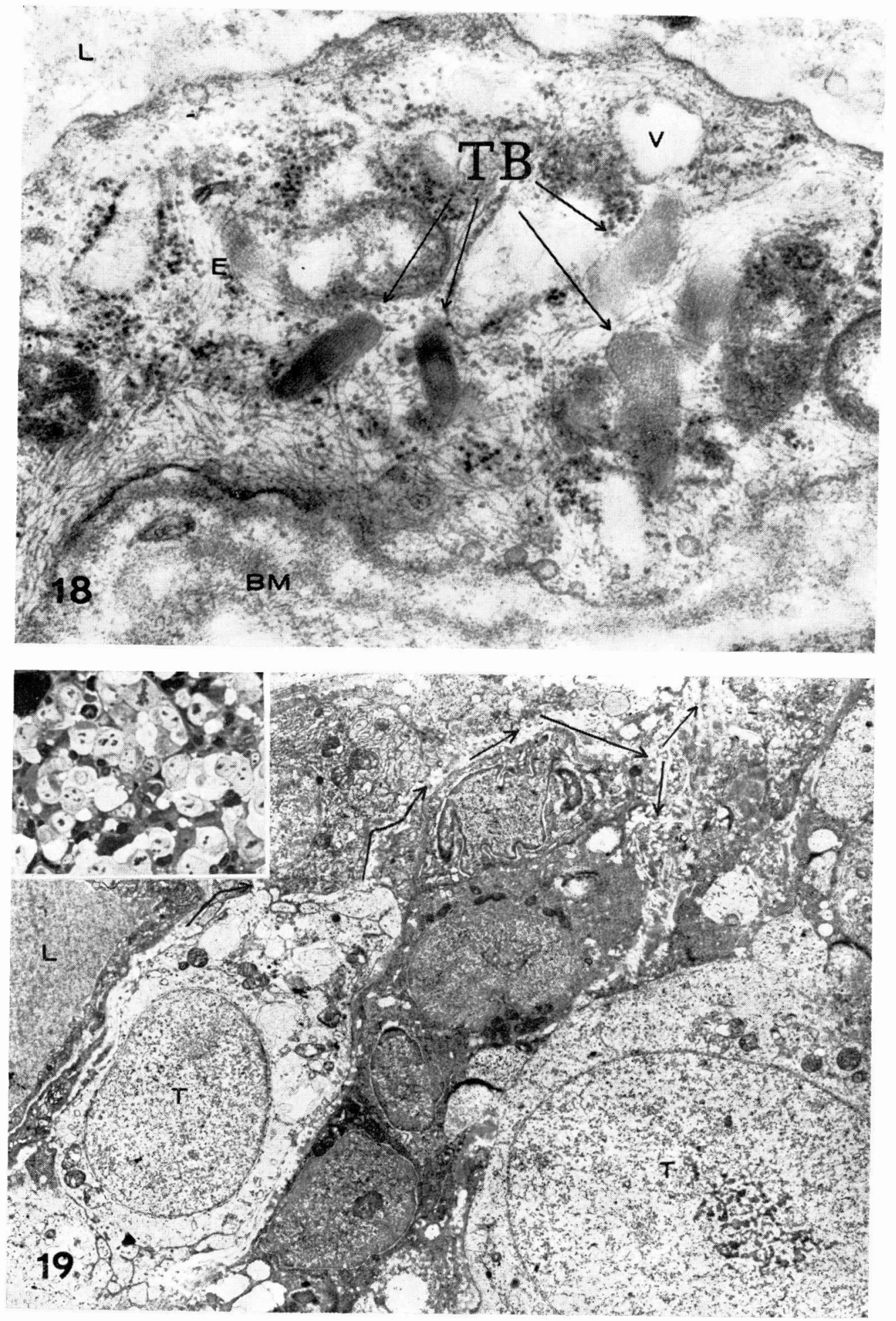

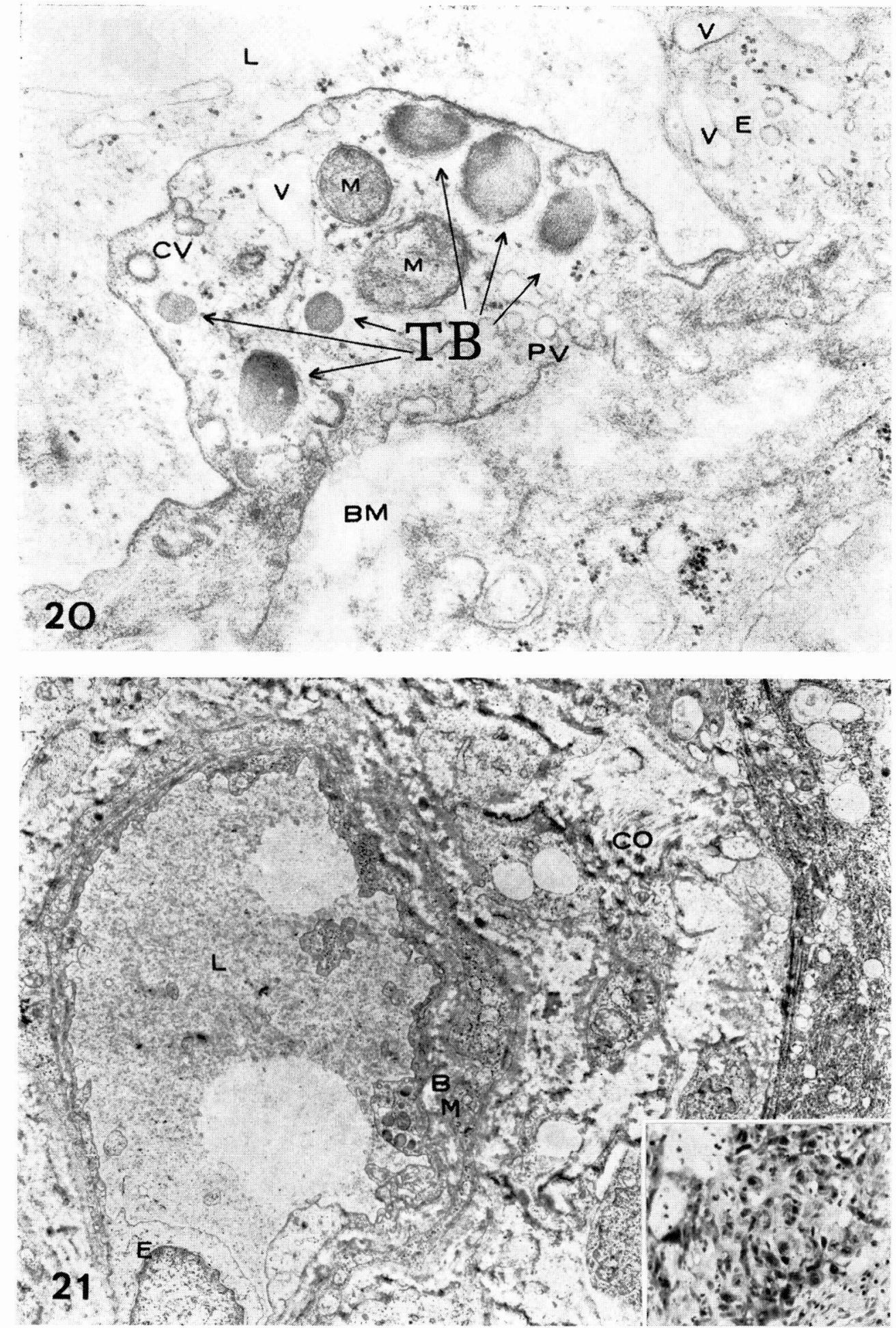

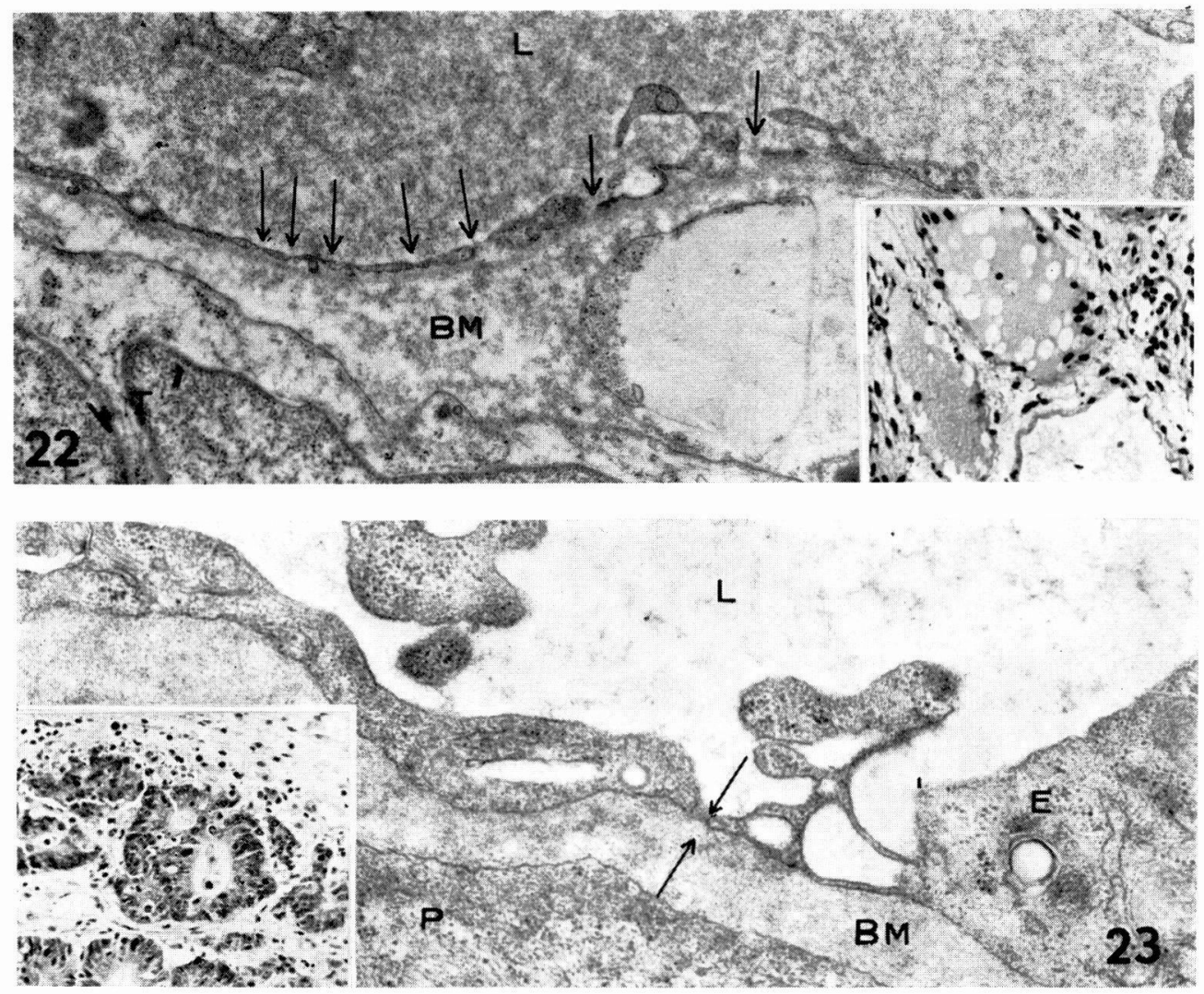

Fig. 18 Capillary in a pinealoma showing tubular bodies (arrows) and increased pinocytotic vesicles and cytoplasmic filaments. The basement membrane is loose and redundant. $\times 51,000$

Fig. 19 Capillary in a pinealma. The basement membrane is filled with collagen fibers. It seems to merge continuously into the extracellular space. $\times 5,500$ Inset: Toluidine blue specimen two cell pattern pinealoma $5 \times 40$

Fig. 20 High magnification view of apart of endothelial cells in a teratoma with choriocarcinoma. Tubular bodies (arrows) and coated, pinocytotic vesicles are seen in the endothelial cytoplasm. $\times 38,000$

Fig. 21 Capillary in a teratoma with choriocarcinoma. The perivascular basement membrane is distended and contains collagen fibers. $\times 6,500$

Inset: H.E. specimen teratoma with choriocarcinoma $5 \times 20$

Fig. 22 Capillary in a hemangioma showing fenestrations (arrows). $\times 12,000$ Inset: H.E. specimen cavernous hemangioma $5 \times 20$

Fig. 23 Capillary in metastatic brain tumor. Arrow indicates endothelial fenestration.

Inset: H.E. specimen papillary adenocarcinoma $5 \times 20$ 